\title{
Finishing of nickel matrix composite coatings
}

\section{Tomasz Cyryl Dyl*, Robert Starosta}

Gdynia Maritime University, Faculty of Marine Engineering, Department of Marine Materials and Technology, Morska Street 81-87, 81-225 Gdynia, Poland, dylu@am.gdynia.pl, starosta@am.gdynia.pl

* Correspondence: dylu@am.gdynia.pl,

\begin{abstract}
Metal matrix composite are used in such fields of technology, such as: aerospace, electronics, energy, industry, defense, automotive, aviation, shipbuilding, and more. Composite coatings of ceramic - metals is used primarily to enhance the durability of machine parts. Therefore, new materials are permanently looked for, what has resulted in the past in development of composite materials. The coatings dispersed are consisting of metallic matrix (metals and their alloys) and small non-metallic particles. The deposition of ceramic particles simultaneously with metallic matrix leads often to composite coatings possessing properties much better than those of metallic coating. The nickel and less often, other iron group elements are usually used as a matrix and $\mathrm{Al}_{2} \mathrm{O}_{3}$ as tough particles. The welding technology of applying alloy and composite coatings is widely used. The technology of infrasound thermal spraying of metal matrix composite coatings was presented. It is a simple technology and a very useful one in ship machinery regeneration during the cruise craft (e.g. internal combustion engines, torque pumps, separators). The metal matrix composite coatings must undergo finishing due to high surface roughness after application. In the article to used finishing by plastic working and machining of coatings nickel matrix composite was proposed.
\end{abstract}

Keywords: finishing; plastic working; machining; nickel matrix composite; coatings

\section{Introduction}

The paper presents the possibility of using plastic working and machining to create the required roughness of the surface layer of the coating. This presents the findings of the research into the possibility of using the cold plastic working (cold rolling and cold pressing) to obtain the selected properties of the flame sprayed alloy coatings and composite coatings. The alloy coatings had a single-phase structure, of the maximum $10 \%$ aluminum solubility in the crystal lattice of nickel, whereas in the composite coatings the volume fraction of nonmetallic material $\mathrm{Al}_{2} \mathrm{O}_{3}$ was $15 \%$ and $30 \%$. And proposes finishing turning for the flame sprayed coatings. Alloy coatings $\mathrm{Ni}-5 \% \mathrm{Al}$ and composite $\mathrm{Ni}-5 \% \mathrm{Al}-15 \% \mathrm{Al}_{2} \mathrm{O}_{3}$ were investigated, which substantial powders have been obtained by flame spraying using the "Casto-Dyn 8000" torch delivered by Messer Eutectic Castolin.

\section{Forming the surface layer of composite coatings by plastic working}

\subsection{Introduction to the topic of finishing coatings by plastic working}

The object has been aimed to preliminary analyse the possibility of replacement of the traditional finishing methods, by surface plastic working. Samples with steel C45 and coating were subjected to cold rolling and pressing to obtain the following values of actual draft: $\varepsilon_{\mathrm{h}}=$ $12 \%$. Flame-sprayed coatings were characterised by a considerable value of parameter Ra. The surface roughness obtained by flame spraying is not satisfactory in respect to the service qualities because as large values unclear as $\mathrm{Ra}=13 \mu \mathrm{m}$ are obtained [1,2]. 
Therefore the coatings should be subjected to finishing in order achieving the required surface quality. The plastic working caused decrease surface roughness. Minimum value of $\mathrm{Ra}$ parameter was observed after hot rolling. It was found that maximal roughness was presented after pressing. The corrosion tests were performed in $0.01 \mathrm{M} \mathrm{H}_{2} \mathrm{SO}_{4}$ solution by potentiokinetic technique. The corrosion rate was dependent on method of plastic working. The increasing drafts resulted in rise corrosion current density and decrease in value of corrosion potential $[3,4,5,6]$. In the papers $[7,8,9]$ presented numeric analysis of the rolling process of bimetal plates. Model research of rolling it was stated that there is a possibility of plastic working by means of finishing flame spray coating. Therefore the experiments were performed to test the processes of rolling and pressing of steel specimens coated with alloy and composite coatings with ceramic dispersed phase and corrosion properties after plastic working.

\subsection{Research method by plastic working}

The research was carried out coatings of nickel - base alloy and nickel - matrix composite were applied on the base of C45 steel by subsonic flame spraying using in the Gdynia Maritime University, Faculty of Marine Engineering, Department of Marine Materials and Technology. Coatings were made with such materials as powder ProXon 21021 (Ni-94\%, $\mathrm{Al}-5 \%, \mathrm{~B}-1 \%)$ and its mixture with powder MetaCeram $28020\left(\mathrm{Al}_{2} \mathrm{O}_{3}-97.7 \%, \mathrm{TiO}_{2}-2.2 \%\right.$, $\left.\mathrm{SiO}_{2}-0.1 \%\right)[1,2]$, the powders were produced by Castolin. Volume concentrations of nonmetallic compound $\mathrm{Al}_{2} \mathrm{O}_{3}$ in the obtained coatings: $15 \%$ and $30 \%$. The process of flame spraying of the alloy coatings can be characterised by the following parameters [2-5]: acetylene pressure: $0.07 \mathrm{MPa}$, oxygen pressure: $0.4 \mathrm{MPa}$, distance between the burner and sprayed surface: $150 \mathrm{~mm}$, number of layers applied: 6 , obtained coating thicknesses $h_{p}=0.6$ $\mathrm{mm}$. Rolling and pressing of alloy and composite coatings was performed in the Laboratory of Plastic Working of the Faculty of Mechanical Engineering, Gdańsk University of Technology. Specimens were upended in the cold process on a hydraulic press ZD20, at real draft $\varepsilon_{\mathrm{h}}=12$ $\%$, unit pressure $900 \mathrm{MPa}$. Cold rolling was performed at the ambient temperature using the laboratory two-high mill with the cylinder diameter $\phi 200 \mathrm{~mm}$ and drum length $250 \mathrm{~mm}$, at draft $\varepsilon_{\mathrm{h}}=12 \%$. As a result of the laboratory tests focused on rolling and pressing of coated flat specimens it was found that volume content of non-metallic compound $\mathrm{Al}_{2} \mathrm{O}_{3}$ has a considerable effect on the change of Ra parameter, which characterises surface roughness, and also on the change of the composite coating hardness. Assessment of the strain effect on the coating structure was performed with the use of optical microscope Axiovert 25 at $200 \times$ magnification. Adhesion of the alloy and composite coatings was assessed in accordance with standard using the following two qualitative methods: scratch method and temperature change method. The assessment was made by viewing the surface with stereoscopic microscope MBC-9 at fivefold magnification. The coating adhesion was considered as good if no lamination, bubbles or exfoliation had been observed.

Microhardness was measured with the use of Vickers Hardness Tester FM-800. The load of $0.49 \mathrm{~N}$ was applied for 10 seconds at the ambient temperature. To assess the effect of the technological process on microhardness of the processed coatings, relative hardening of the superficial layer was determined in accordance with the following formula :

$$
S_{\mathrm{u}}=\frac{H V_{1}}{H V_{0}} 100 \%
$$

where: $S_{\mathrm{u}}$ - relative hardening,

$H V_{0}$ - microhardness before plastic working,

$H V_{1}-$ microhardness after plastic working. 
Surface roughness after plastic working was measured with a profilometer Hommel - Etamic T8000. The assumed measurement section length of test sample was $4.8 \mathrm{~mm}$ and $0.8 \mathrm{~mm}$ for the elementary section. The measurements were performed according to the principles contained in ISO standards EN ISO 4287 and EN ISO 13565. According to the measurement of the arithmetical mean deviation of the roughness profile ( $\mathrm{Ra}$ ), the surface roughness reduction ratio was determined using the formula below:

$$
K_{\mathrm{Ra}}=\frac{R a^{\prime \prime}}{R a}
$$

where: $K_{\mathrm{Ra}}$ - surface roughness reduction,

$R a$ "- material surface roughness before plastic working,

$R a$ - material surface roughness after plastic working.

Measurement of corrosion resistance of the coatings was performed using electrochemical test in a three-electrode system. A specimen of the surface area of $0.75 \mathrm{~cm}^{2}$ was degreased with acetone and then placed in a vessel containing $500 \mathrm{~cm}^{3}$ of $0.01 \mathrm{M} \mathrm{H}_{2} \mathrm{SO}_{4}$ at the ambient temperature together with an auxiliary (polarising) electrode made of platinum-coated titanium and the reference electrode (saturated calomel electrode). Before the measurements were taken, the specimens had been exposed to an electrolyte for one hour to enable stabilisation of corrosion potential. The whole time the measurement the electrolyte was constantly stirred. For the duration of the experiments, polarisation curves $i=f(E)$ were recorded in the range $\pm 150 \mathrm{mV}$ from the corrosion potential. Cathodic curve was recorded first, and then the anodic one. In all cases, the potential change rate was $10 \mathrm{mV} / \mathrm{min}$. Electrochemical studies were performed ATLAS device 053 EU \& IA.

\subsection{Results of experiments by plastic working}

Introduction of ceramic dispersed phase itself increases hardness of the coatings base. Hence plastic working as the strengthening finish treatment is advisable mainly for alloy coatings. After pressing, an increase in alloy coatings hardness even up to $80 \%$ is observed, whereas for composite coatings with $15 \%$ content of $\mathrm{Al}_{2} \mathrm{O}_{3}$ the coatings base hardness rises by $50 \%$. In the case of cold rolling, even greater hardening ratios for both alloy and composite coatings $\left(93 \%\right.$ for $\mathrm{Ni}-5 \% \mathrm{Al}$ coating and $66 \%$ for coating $\mathrm{Ni}-5 \% \mathrm{Al}-15 \% \mathrm{Al}_{2} \mathrm{O}_{3}$ ) are attainable. Draft and unit pressure applied in plastic working of the steel specimens with alloy and composite coatings caused only plastic strain of the coating material. In the base steel, no structure change testifying to its plastic strain was observed. Metallographic study showed reduction in the porousness of the alloy and composite coatings subjected to plastic working (Fig. 1). Application of plastic working finish for flame-sprayed coatings results in a significant improvement of the surface quality. After plastic working, the average arithmetical roughness profile is to twenty times as lesser as the average arithmetical roughness profile of the coating before to plastic working. As a result of rolling, parameter Ra reaches much lower values comparing to the roughness profile deviation after pressing. Flame-sprayed alloy coatings were characterised by greatly developed real surface. The average arithmetical roughness $(\mathrm{Ra})$ was around $13 \mu \mathrm{m}$. The applied methods of plastic working as coatings finishing allowed for significant reduction of the value of considered the parameter. The minimum value of $\mathrm{Ra}=0.44 \mu \mathrm{m}$ for $\varepsilon_{\mathrm{h}}=12 \%$ was achieved for cold rolled coatings, whereas the pressing process allowed for obtaining the surface roughness of the order of $\mathrm{Ra}=1.23$ $\mu \mathrm{m}$. Loads applied within plastic working of the steel specimens with alloy and composite coatings caused only plastic strain of the coating material. Table 1 shows corrosion study results for coatings of nickel - base alloy and nickel - matrix composite with ceramic dispersed phase (volume fraction ceramic dispersed phase - $\mathrm{C}_{\mathrm{DPh}}=0 \%, 15 \%, 30 \% \mathrm{Al}_{2} \mathrm{O}_{3}$ ). 
a)

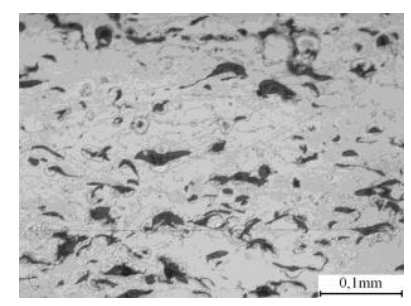

b)

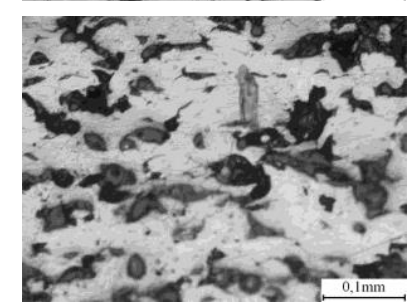

c)

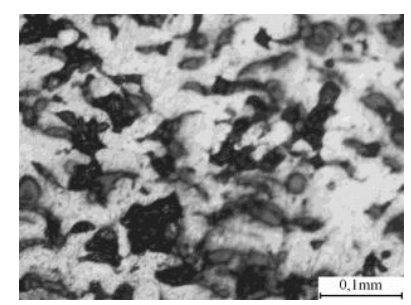

d)

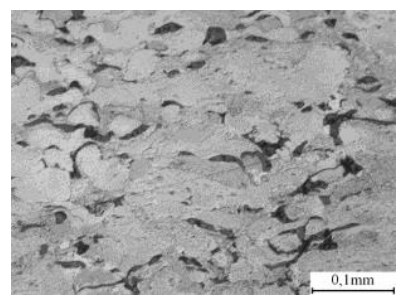

e)

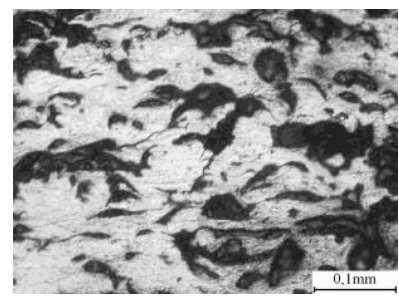

f)

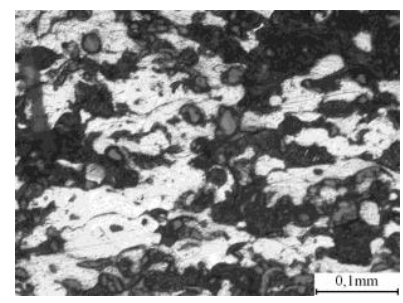

Figure 1. The alloy and composite coatings, microstructure for different volume fraction ceramic dispersed phase, after rolling [3]: a) $\mathrm{C}_{\mathrm{DPh}}=0 \% \mathrm{Al}_{2} \mathrm{O}_{3} ;$ b) $\mathrm{C}_{\mathrm{DPh}}=15 \% \mathrm{Al}_{2} \mathrm{O}_{3}$; c) $\mathrm{C}_{\mathrm{DPh}}=30 \% \mathrm{Al}_{2} \mathrm{O}_{3}$; and after pressing: d) $\mathrm{C}_{\mathrm{DPh}}=0 \% \mathrm{Al}_{2} \mathrm{O}_{3} ;$ e) $\mathrm{C}_{\mathrm{DPh}}=15 \% \mathrm{Al}_{2} \mathrm{O}_{3} ;$ f) $\mathrm{C}_{\mathrm{DPh}}=30 \% \mathrm{Al}_{2} \mathrm{O}_{3}$

Table 1. The results of the corrosion testing for alloy and composite coatings with volume fraction ceramic dispersed phase

\begin{tabular}{ccccc}
\hline Manufacturing Processing & $\begin{array}{c}\mathbf{C}_{\text {DPh }} \\
{[\mathbf{\%}]}\end{array}$ & $\begin{array}{c}\mathbf{\varepsilon} \\
{[\mathbf{\%}]}\end{array}$ & $\begin{array}{c}\mathbf{j} \text { corr } \\
{\left[\boldsymbol{\mu} \mathbf{A} / \mathbf{c m}^{2}\right]}\end{array}$ & $\begin{array}{c}\mathbf{E}_{\text {corr }} \\
{[\mathbf{m V}]}\end{array}$ \\
\hline flame sprayed & 0 & - & 257 & -173 \\
pressing & 0 & 12 & 319 & -199 \\
rolling & 0 & 12 & 249 & -205 \\
\hline flame sprayed & 15 & - & 139 & -172 \\
pressing & 15 & 12 & 127 & -397 \\
rolling & 15 & 12 & 114 & -399 \\
\hline flame sprayed & 30 & - & 103 & -179 \\
pressing & 30 & 12 & 221 & -435 \\
rolling & 30 & 12 & 189 & -489 \\
\hline
\end{tabular}

The figure 2 influence of the ceramic dispersion in the nickel matrix composite coatings on corrosion current density after flame sprayed and after plastic working is presented. Corrosion current density for the composite coatings after plastic working is twice lower compared to the alloy coatings. This may prove that a lower rate of electrochemical corrosion of conduct. The figure 3 shows influence of the ceramic dispersion in the composite coatings on corrosion potential after sprayed and after plastic working. The corrosion potential for composite coatings have been treated with plastic working is two to three times smaller than for the alloy and composite coatings after spraying. Increased content of ceramic dispersion reduces the corrosion potential, and therefore increases the capacity of electrochemical corrosion. Electrochemical corrosion tests proved that the proposed finishing methods aiming to reduce 
roughness of flame sprayed coatings resulted in the corrosion potential value shift towards the anodic values.

Application of pressing increased the coating corrosion rate $\mathrm{j}_{\text {corr }}$ and potential corrosion $\mathrm{E}_{\text {corr }}$ compared to that before plastic working (Table 1). The figure 4 shows potentiostatic polarization curves on the nickel matrix composite coatings for $15 \% \mathrm{Al}_{2} \mathrm{O}_{3}$ ceramic dispersion after plastic working. The smaller the value of corrosion current density can provide a lower rate of electrochemical corrosion in the case of alloy and composite coatings treated plastic working. The smaller the value of the corrosion potential may be characterized by a greater ability to act electrochemical corrosion. Corrosion investigation made in $0.01 \mathrm{M} \mathrm{H}_{2} \mathrm{SO}_{4}$ showed that in most cases of plastic working operations, there was an increase in the corrosive current density accompanied by the drop in the corrosion potential.

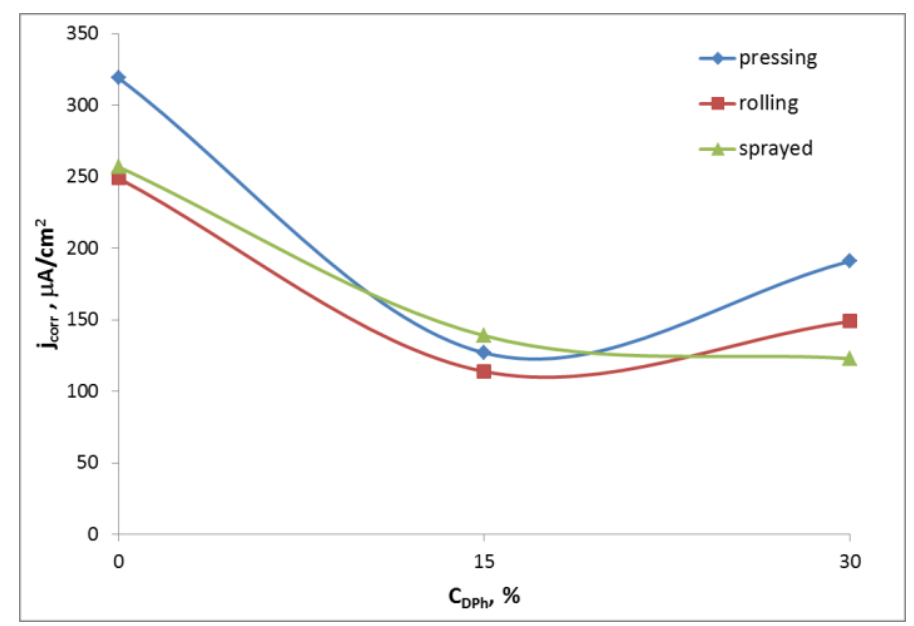

Figure 2. The effect of the ceramic dispersion in the nickel matrix composite coatings on corrosion current density after pressing, rolling, flame sprayed

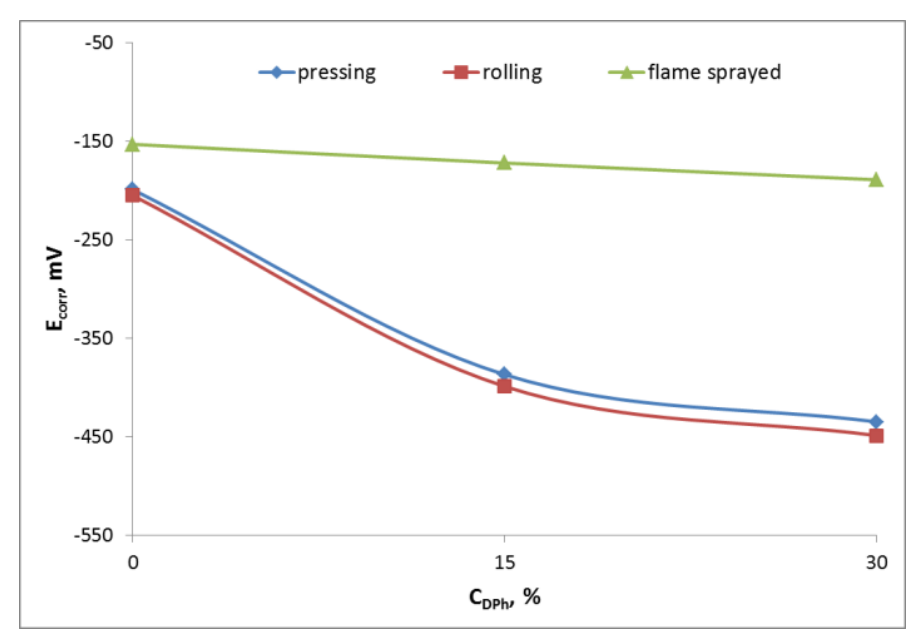

Figure 3. The effect of the ceramic dispersion in the nickel matrix composite coatings on corrosion potential after pressing, rolling, flame sprayed 


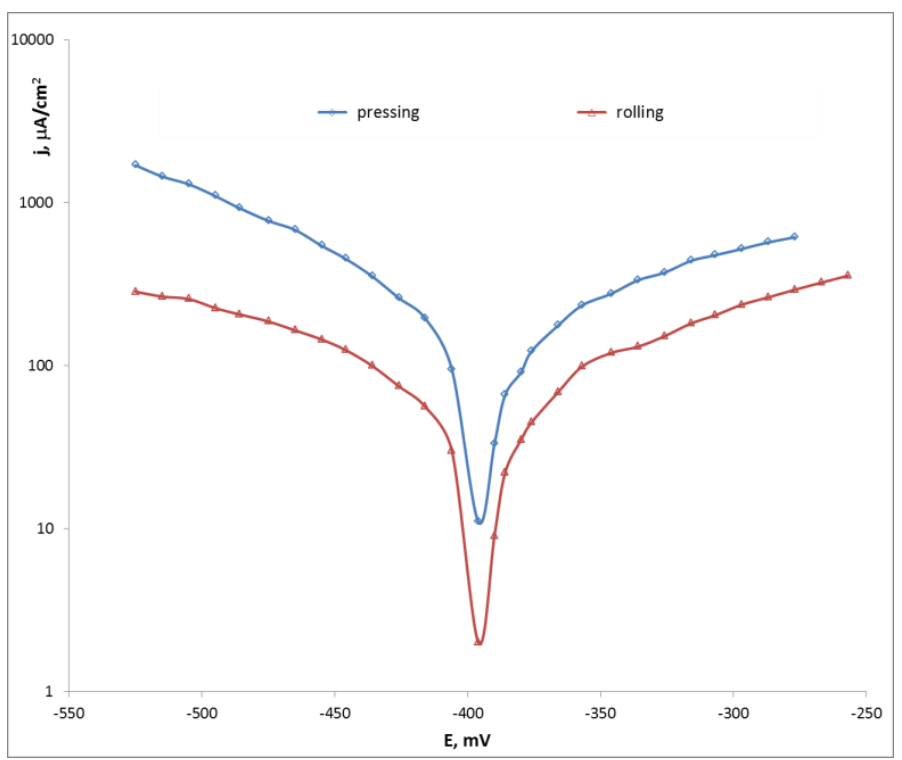

Figure 4. The potentiostatic polarization curves for composite coatings with volume fraction ceramic dispersed phase $\mathrm{C}_{\mathrm{DPh}}=15 \% \mathrm{Al}_{2} \mathrm{O}_{3}$ after plastic working pressing and rolling

The data presented in figure 5 indicate that the greater content of dispersion phase in composite coatings, the greater roughness is achieved. Also, the surface roughness reduction ratio reaches its greatest values for alloy coatings. The lowest values of the roughness reduction ratio occur for composite coatings with $30 \%$ content of $\mathrm{Al}_{2} \mathrm{O}_{3}$.

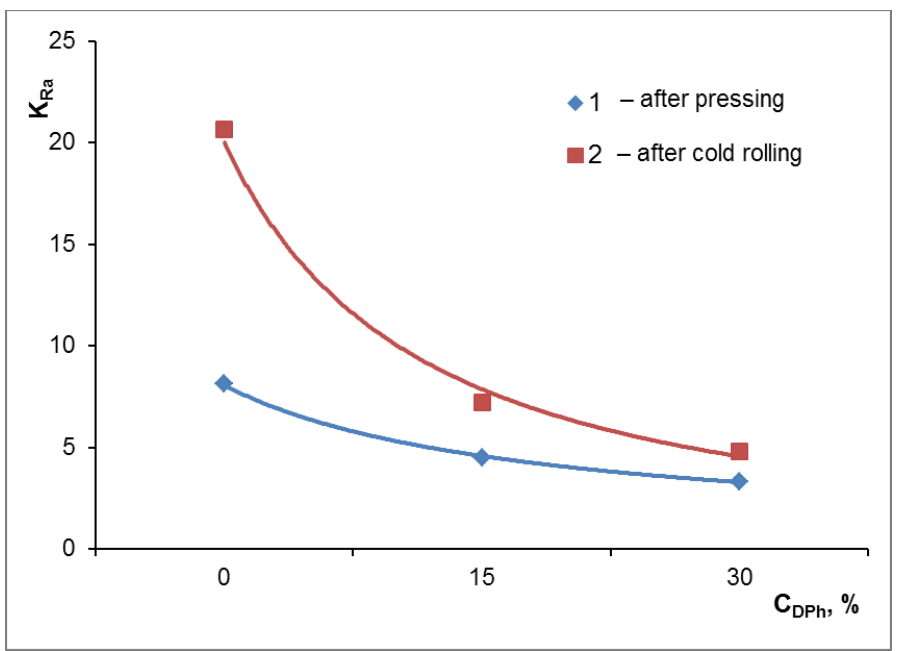

Figure 5. The effect of volume fraction ceramic dispersed phase $\mathrm{C}_{\mathrm{DPh}}$ in obtained composite coatings on surface roughness reduction ratio after cold plastic working, 1 - after pressing, 2 - after cold rolling

The experiments allowed for determination - based on the measurements of microhardness and roughness profile after flame spraying and after plastic working - that the dispersion phase content in the composite coating has a significant effect on strengthening and smoothness of the coating surface. The dependency of the ratio of relative strengthening of the composite coating on the nickel base, on the volume content of non-metallic material $\mathrm{Al}_{2} \mathrm{O}_{3}$ is shown in figure 6. It shows that an increase in the percentage content of alumina is accompanied by a decrease in the coating strengthening ratio after plastic working. Another important thing is that after rolling and also after pressing, the specimens with alloy coatings gain much greater microhardness compared to the specimens with composite coating. Therefore lower content of dispersion phase results in greater strengthening of the coating base. 
Introduction of $\mathrm{Al}_{2} \mathrm{O}_{3}$ dispersion phase itself increases hardness of the coatings' base. Hence plastic working as the strengthening finish is advisable mainly for $\mathrm{Ni}-\mathrm{Al}$ alloy coatings. After pressing, an increase in $\mathrm{Ni}-\mathrm{Al}$ alloy coatings' hardness by up to even $80 \%$ is observed, whereas for composite coatings with $15 \%$ content of $\mathrm{Al}_{2} \mathrm{O}_{3}$ the coating's base hardness rises by $50 \%$. In the case of cold rolling, even greater hardening ratios for both alloy and composite coatings $\left(S_{\mathrm{u}}=93 \%\right.$ for Ni-Al coating and $\mathrm{S}_{\mathrm{u}}=66 \%$ for coating Ni-Al$15 \% \mathrm{Al}_{2} \mathrm{O}_{3}$ ) are attainable. The obtained results of hardness measurements showed that all the proposed methods of plastic working finish caused strengthening of the investigated coatings. The greatest ratio of coating strengthening occurred in the cold rolled and cold pressed specimens, whereas in hot rolled specimens the strengthening ratio was the least.

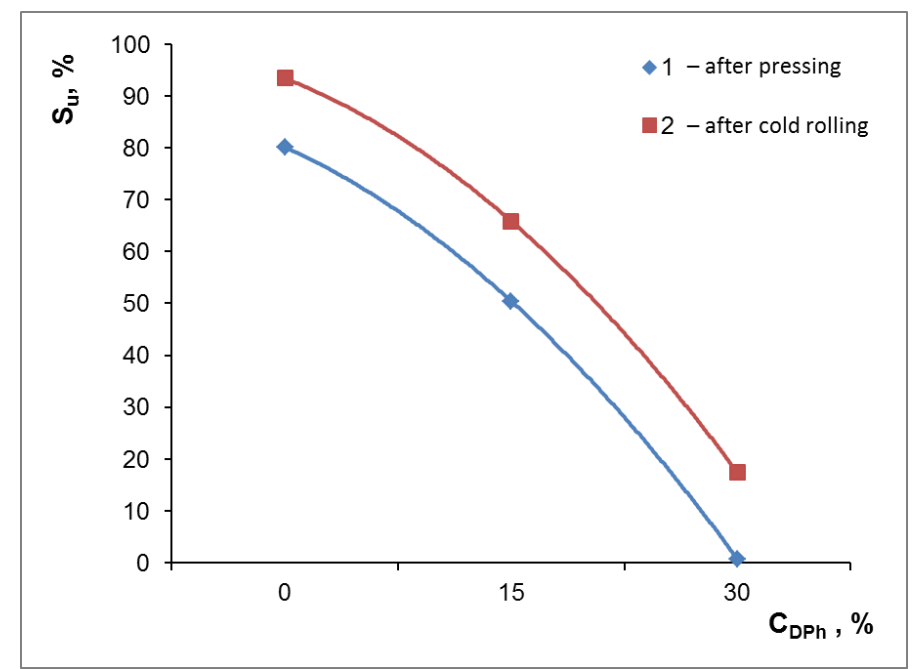

Figure 6. The effect of volume fraction ceramic dispersed phase $\mathrm{C}_{\mathrm{DPh}}$ in obtained composite coatings on relative strengthening ratio after cold plastic working, 1 - after pressing, 2 - after cold rolling

The flame sprayed alloy coatings were characterised by greatly developed actual surface. The applied methods of plastic working as coatings finishing allowed for significant reduction of the value of the parameter in question. The minimum value of $R_{a}=0.38 \mu \mathrm{m}$ was achieved for hot rolled coatings at actual draft $\varepsilon_{\mathrm{h}}=12 \%$, whereas the pressing process allowed for obtaining the surface roughness of the order of $\mathrm{Ra}=1.23 \mu \mathrm{m}$.

\subsection{Summary by plastic working}

The based on experimental data states that the ceramic dispersion content in the composite coating has a significant effect on strengthening and quality of the coating subjected to plastic working. The following conclusions were also reached:

Application of plastic working as a strengthening method of finishing is advisable mainly for alloy coatings, where significant strengthening occurs, and the ratios of coating strengthening are $80 \%$ - after pressing, and $93 \%$ - after rolling;

Application of plastic working as a strengthening finish method is also advisable for composite coatings with $15 \%$ content of $\mathrm{Al}_{2} \mathrm{O}_{3}$ where hardness of the coating base increases by $50 \%$ - after pressing and by $66 \%$ - after rolling; minimum values of the surface roughness is obtained after rolling;

The coating subjected to cold plastic working gained a more homogeneous structure as most of the pores, which had occurred after flame spraying, were closed;

The lower value of corrosion potential in coating plastic working composite treated shows that the increase of ceramic dispersion $\mathrm{Al}_{2} \mathrm{O}_{3}$ can affect the ability to increase the occurrence of electrochemical corrosion in the nickel matrix composite coatings; 
The smaller the value of corrosion current density can provide a lower rate of electrochemical corrosion in the case of composite coatings after plastic working;

The lowest corrosion current density occurs in the composite coatings containing $15 \% \mathrm{Al}_{2} \mathrm{O}_{3}$ ceramic dispersion after rolling and after pressing.

\section{Finishing the surface layer of composite coatings by machining}

\subsection{Introduction to the topic of finishing coatings by machining}

The processes of production and regeneration of products with applied metal matrix composite coating are recognized among engineers, technologists, because of the possibility of increasing the performance characteristics of the surface layer (strength, tribological and corrosion resistance and decorative aspect). Metal matrix composite and metal alloy and coatings containing in-metal matrix dispersion inclusions of non-metallic phase is characterized by high resistance to tribological and corrosion wear [10, 11, 12]. Metal matrix composite are used in such fields of technology, such as: aerospace, electronics, energy, industry, defense, automotive, aviation, shipbuilding, and more. Based on a literature review, in the study it has been considered composite coatings based on nickel with aluminum [13, $14,15,16]$.

The flame sprayed coatings are characterized by porosities, oxide inclusions and the presence of a strongly developed surface float. In order to obtain a suitable surface texture coatings finishing must be used. For this purpose, turning and grinding can be applied. The paper proposes finish turning for the flame sprayed coatings. Alloy coatings $\mathrm{Ni}-5 \% \mathrm{Al}$ and composite $\mathrm{Ni}-5 \% \mathrm{Al}-15 \% \mathrm{Al}_{2} \mathrm{O}_{3}$ were investigated, which substantial powders have been obtained by flame spraying using the "Casto-Dyn 8000" torch delivered by Messer Eutectic Castolin company. In practice, the thermally sprayed coatings are machined using the same tool as for machined surface. For example, a company Messer Eutectic Castolin proposed multi tool with a square or cylindrical inserts. Cutting tools, cutting elements should be made of cubic boron nitride or diamond. Also the insert tool made of tungsten carbide is allowed [17]. During the turning of alloy and composite coatings the durability of the insert is usually short. It is therefore important to determine the length of spiral cutting. This is the length cutting, which are chosen for recommended cutting, thus allowing for a reliable process. Length of spiral cutting is dependent on the insert geometry and grade, depth of cut and material that shall be subject machined [18].

\subsection{Research methodology of finishing coatings}

To determine the parameters of machining the alloy coatings and composites based on nickel flame sprayed onto the substrate steel, the preliminary study was conducted for straight turning of high precision. Such turning has been realized with different cutting speed $\left(v_{c}=45\right.$ $\div 214 \mathrm{~m} / \mathrm{min})$, feed rate $(f=0.06 \div 0.2 \mathrm{~mm} / \mathrm{rev})$ and depth of cut $\left(a_{p}=0.05 \div 0.3 \mathrm{~mm}\right)$. Based on analysis of test results, it was determined that the best surface quality was obtained for samples of coated steel, nickel based alloys, using the cutting speed $v_{c}=214 \mathrm{~m} / \mathrm{min}$ in the case of treatment with inserts of borazon, $v_{c}=107 \mathrm{~m} / \mathrm{min}$ in the case of inserts treated with tungsten carbide cutting. Then it was determined that the best gain of the sample surface quality of coated steel composite was obtained for cutting speed $v_{c}=157 \mathrm{~m} / \mathrm{min}$, in the case of treatment with CBN inserts, $v_{c}=83 \mathrm{~m} / \mathrm{min}$ after treatment tungsten carbide inserts. For machining alloy coatings and composites used feed $f=0.06 \mathrm{~mm} / \mathrm{rev}$ and depth of cut $a_{p}=0.3$ $\mathrm{mm}$. The determination of the optimal geometry of the cutting tool is synonymous with the selection of the optimum shape and dimensions of the insert. 
The appropriate holder and edged tiles were chosen, which could be square, round, triangular, trigon, made of tungsten carbide (with grades: GC2015, GC3205, GC3210, GC3215, GC4015, H10F) and cubic boron nitride (CBN, grade CB7015). The research program is presented in Table 2. Surface texture of the alloy and composite coatings was measured with a Hommel Tester T1000 profilometer. During the turning of alloy and composite coatings is usually short durability of the insert. It is therefore important to determine the length of spiral cutting. This is the length cutting, which are chosen for recommended cutting, thus allowing for a reliable process. Length of spiral cutting is applied to the insert, geometry, and grade, depth of cut and material that shall be subject machined. Length of spiral cutting ( $L S C)$ can be calculated from the formula [18]:

where:

$$
L S C=\frac{\Pi d l}{1000 f}
$$

$d$ - the diameter of the workpiece in the machined surface, [mm],

$l$ - length of the cutting surface, $[\mathrm{mm}]$,

$f$ - feed rate, $[\mathrm{mm} / \mathrm{rev}]$.

Table 2. The shape, type and grade inserts

\begin{tabular}{ccc}
\hline Insert Shape & Insert Type & Insert Grade \\
& & \\
\hline Square & SNGA 120408 S01030A & CB7015 \\
Round & N123J1-0600-RE & CB7015 \\
Triangular & TNMX 160408- WM & GC4015 \\
Triangular & TNMG 160408 - 23 & H10F \\
Trigon & WNMG 080408 - WF & GC2015 \\
Trigon & WNMG 080408 S01030A & CB7015 \\
Trigon & WNMA 080408 - KR & GC3205 \\
Trigon & WNMG 080408 - KM & GC3205 \\
Trigon & WNMG 080408 - KM & GC3210 \\
Trigon & WNMG 080408 - KF & GC3215 \\
\hline
\end{tabular}

\subsection{Results of research for machining nickel matrix composite coatings}

The study allowed for determination, that there are relationships between the surface texture of alloy and composite coatings and the type of grade used and the shape of the inserts. Trigon insert WNMG 080408 S01030A and round insert N123J1-0600-RE 7015 of CBN was characterized by a smaller flank wear as compared to a square insert with SNGA 120408 S01030A 7015 of CBN.

Surface roughness of the surface texture alloy coatings of $\mathrm{Ni}-5 \% \mathrm{Al}$ turned insert trigon $(\mathrm{Ra}=0,47 \mu \mathrm{m})$ and round $(\mathrm{Ra}=0,39 \mu \mathrm{m})$ is nearly three times smaller than the roughness of the coatings faced a square insert $(\mathrm{Ra}=1,07 \mu \mathrm{m})$. Using the trigon insert made of tungsten carbide determined that the minimum surface roughness of alloy coatings are obtained for grade GC3215 $(\mathrm{Ra}=0,54 \mu \mathrm{m})$. After turning composite $\mathrm{Ni}-5 \% \mathrm{Al}-15 \% \mathrm{Al}_{2} \mathrm{O}_{3}$ using square insert SNGA120408S01030A 7015, specifies that the arithmetical mean deviation of the assessed profile reached a lower value of $\mathrm{Ra}=1.08 \mu \mathrm{m}$ in comparison to the roughness of the surface texture with the trigon insert made of the same grades (CB7015) and also with the trigon of tungsten carbide (about the grades: GC2015, GC3205, GC3210, GC3215) and tungsten carbide (for grades: GC4015, H10F) for triangular inserts. The lowest surface roughness $\mathrm{Ra}=0.65 \mu \mathrm{m}$ is achieved, composite coating turned insert round N123J1-0600-RE 
7015. Round insert after turning composite coatings are characterized by the lowest flank wear compared to the square, trigon and triangular.

Figure 7 shown the arithmetical mean deviation of the assessed profile for alloy Ni$5 \% \mathrm{Al}$ and composite $\mathrm{Ni}-5 \% \mathrm{Al}-15 \% \mathrm{Al}_{2} \mathrm{O}_{3}$ coatings after turned for various type inserts. Parameter (Rpk) of the reduced peak height (which should be the lowest) is characteristic for the upper surface layer that quickly undergoes abrasion after start of i.e. engine running. Reduced depth of roughness profile valley is described by (Rvk) parameter (which should be the highest). It is a measure of the working surfaces ability to keep the lubricant in the valleys created mechanically. Parameter (Rk) defines the core roughness depth (which should be the lowest) (Fig. 8 and Fig. 9). After turning the external cylindrical stainless steel samples with coating of alloys and composites, it was determined, that there were relationships between surface texture and the type of material used and the shape of the tool inserts. Based on analysis of test results, it was determined, that due to obtaining the smallest surface roughness of alloy coatings, it was expedient to use trigon inserts made of tungsten carbide with grade GC3215 and trigon inserts made of cubic boron nitride grade CB7015 and round inserts (CB7015).

Turning surfaces of have been subjected to the external cylindrical stainless steel samples of coated alloys and composites. After experimental studies determined that there are relationships between surface texture and the type of material used and the shape of the tool inserts. Based on analysis of test results determined that due to obtaining the smallest surface roughness alloy coatings, it was expedient to use trigon inserts made of tungsten carbide with grade GC3215 and cubic boron nitride grade CB7015 and round inserts (CB7015).

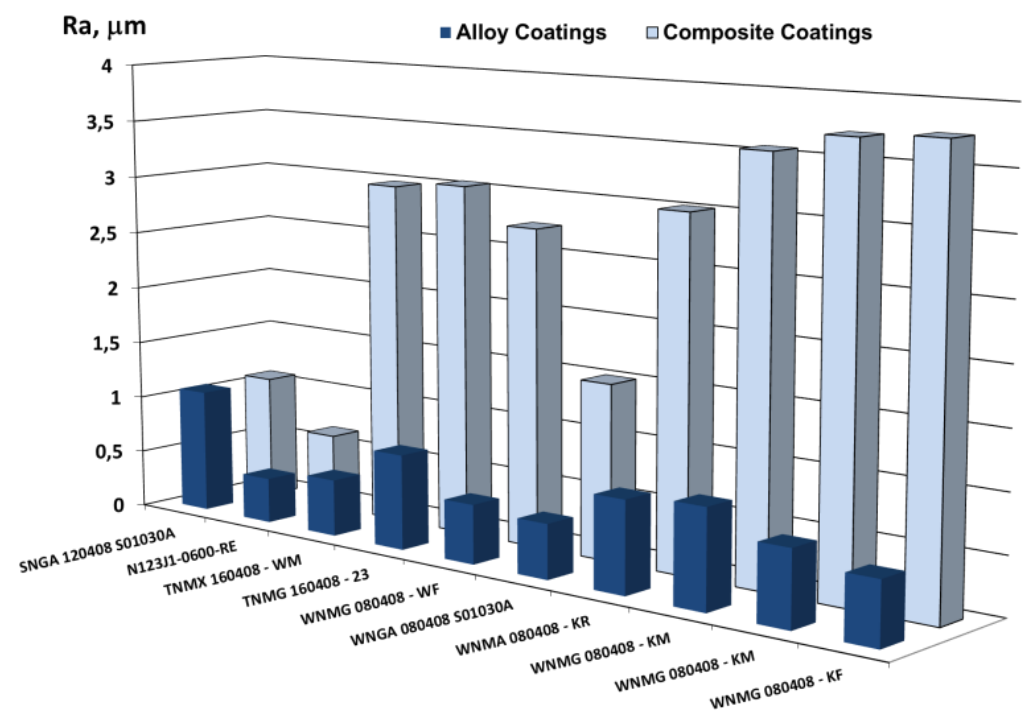

Inserts Type

Figure 7. The arithmetical mean deviation for alloy coatings and for composite coatings with volume fraction ceramic dispersed phase $\mathrm{C}_{\mathrm{DPh}}=15 \% \mathrm{Al}_{2} \mathrm{O}_{3}$ for turned samples inserts according to the research program 


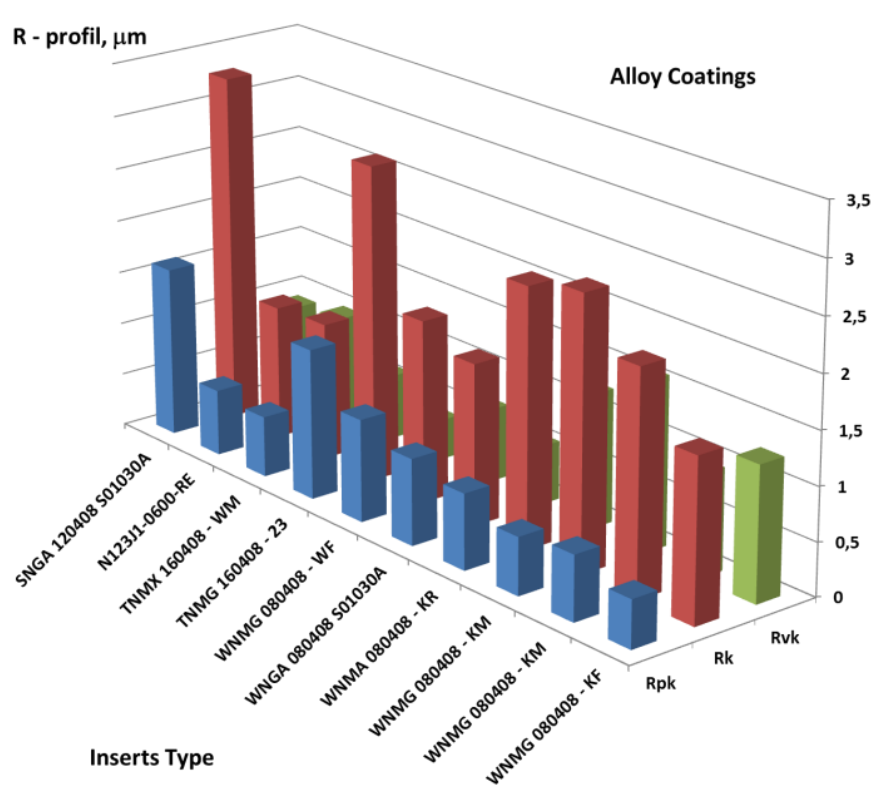

Figure 8. The characterized parameters of the material ratio curve for nickel base alloy coatings after turned for different type inserts

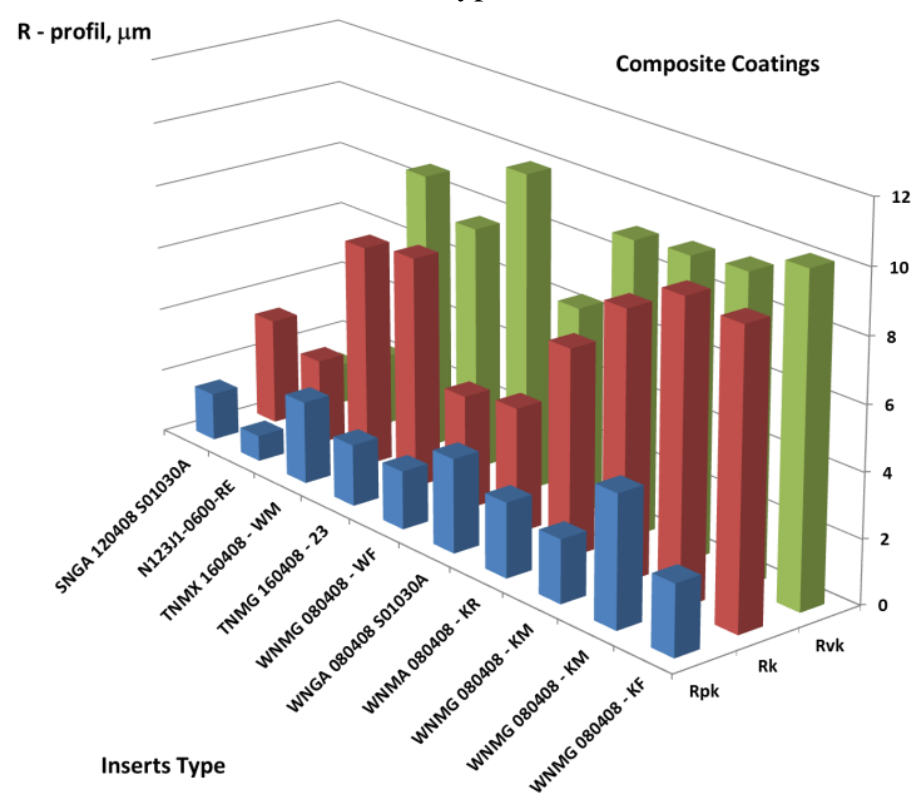

Figure 9. The characterized parameters of the material ratio curve for composite coatings with volume fraction ceramic dispersed phase $\mathrm{C}_{\mathrm{DPh}}=15 \% \mathrm{Al}_{2} \mathrm{O}_{3}$ after turned for different type inserts

For samples with alloy coated $\mathrm{Ni}-5 \% \mathrm{Al}$ subjected to turning determined that the arithmetical mean deviation of the assessed profile and the Abbott-Firestone curve surface roughness parameters take the smallest value (refer with: Fig. 10). On the analysis of test results determined that due to obtaining the smallest surface roughness turned alloy coatings of $\mathrm{Ni}-5 \% \mathrm{Al}$, with the least wear on the insert flank face and tool face, for a constant length of spiral cutting $(L S C=1100 \mathrm{~m})$, targeted to was the use of trigon inserts made of cubic boron nitride on the grade CB7015 and insert grade GC3215 and the round profile of the CB7015.

The roughness of the surface texture of $\mathrm{Ni}-5 \% \mathrm{Al}$ subjected to turning by trigon insert with $\mathrm{CBN}$ is three times smaller than the roughness of the alloy coatings a square insert. Thus, it is advisable not use square inserts for machining alloy coatings. 
Based on analysis of experimental results after turning composite coatings can be determined that the roughness profile parameters and parameter values of the bearing area curve reached the lowest values for samples (refer with: Fig. 11). Figure 12 shown example of the surface topography of the composite coatings turned for inserts with WNMG 080408 S01030A CB7015.

a)

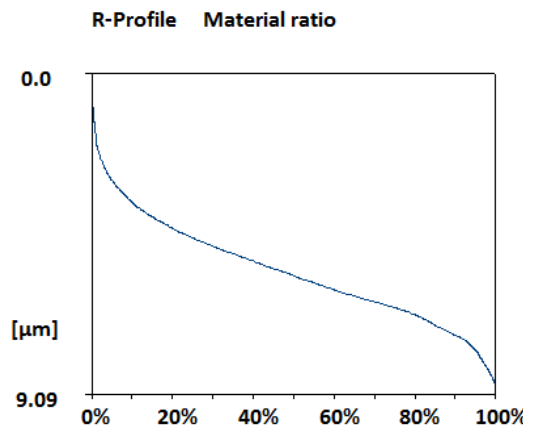

b)

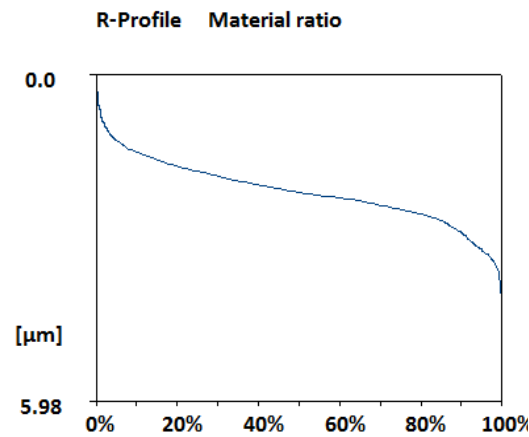

c)

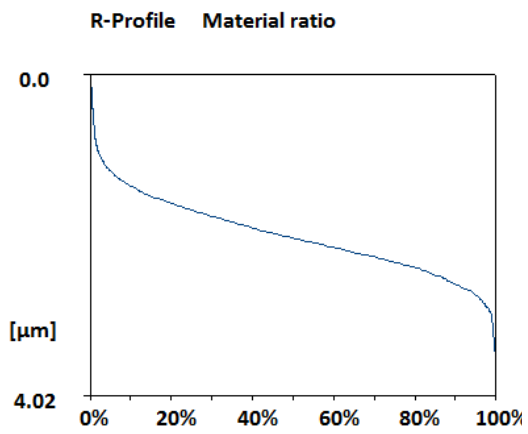

Figure 10. The Abbott-Firestone curve (material ratio curve) surface roughness alloy coatings for inserts with CB7015: a) square SNGA120408S01030A and b) round N123J1-0600-RE and c) trigon WNMG 080408 S01030A

a)

R-Profile Material ratio

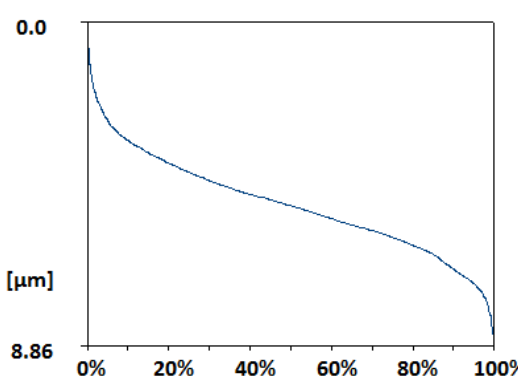

b)

R-Profile Material ratio

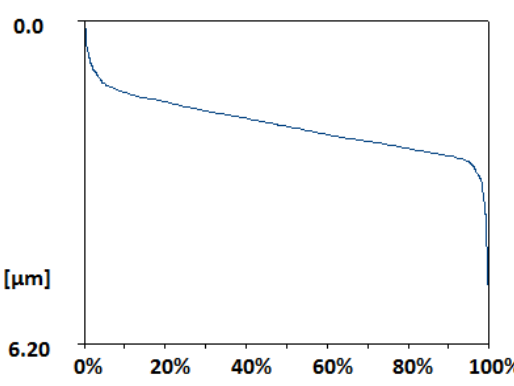

c)

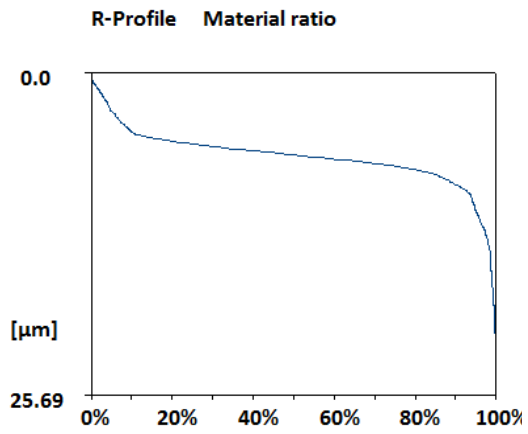

Figure 11. The Abbott-Firestone curve (material ratio curve) surface roughness composite coatings with volume fraction ceramic dispersed phase $\mathrm{C}_{\mathrm{DPh}}=15 \% \mathrm{Al}_{2} \mathrm{O}_{3}$ for inserts with CB7015: a) square SNGA120408S01030A and b) round N123J1-0600-RE and c) trigon WNMG 080408 S01030A 

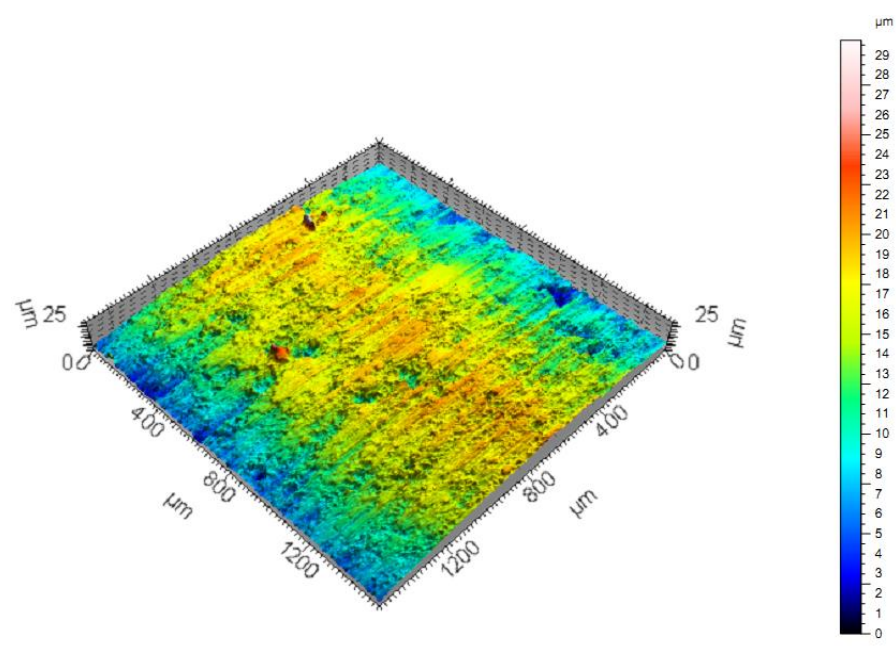

Figure 12. The example of the surface topography of the composite coatings with volume fraction ceramic dispersed phase $\mathrm{C}_{\mathrm{DPh}}=15 \% \mathrm{Al}_{2} \mathrm{O}_{3}$ turned for inserts with WNMG 080408 S01030A CB7015 [19]

\subsection{Summary for finishing nickel matrix composite coatings}

Metal matrix composite coatings obtained by flame spraying have a large surface roughness. Therefore, these coatings must be subjected to finishing. The most commonly used machining (eg, finishing turning, grinding). Flame spray coatings are applied taking into account the allowance for finishing. Finishing should ensure not only adequate coating thickness associated with the nominal size of an object but also to obtain the required surface roughness and waviness. Surface texture is very important where it has a direct influence on the quality of the elements machine parts. Therefore, it has to be defined as precisely as possible with the help of standardized surface texture parameters. The best tool contour and angles, selected the required shape and grade the inserts, you need to obtain a minimum surface roughness. After you finish turning of studies of alloy and composite coatings determined that due to obtaining the smallest surface roughness, with the least wear on the insert flank face and tool face, for a constant length of spiral cutting, targeted to be the use of inserts round with borazon. Alloy and composite coatings used in the production and regeneration, it appears possible to achieve the technological quality of the elements machine parts (eg shafts of centrifugal pumps). It can be argued that due to the surface quality coatings and durability of the turning inserts: for turning shafts of centrifugal pumps with a coating alloy would need to be round and trigon inserts with borazon and trigon with tungsten carbide, for turning shafts of centrifugal pumps with composite coatings should be applied round inserts with borazon.

\section{Conclusions}

In the paper was presented the possibility of using plastic working and finishing to create the required roughness of the surface layer of the coating. The surface layer is very rough and porous after applying the coating by spraying. In order to obtain the proper surface quality of alloy and composite coatings, finishing treatment should be used. In many parts of machines strives to achieve the surface accuracy class very accurate. Therefore often it is required in terms of roughness. It was the arithmetic mean of the ordinates of the surface roughness profile $(\mathrm{Ra}=0.16 \div 1.25 \mu \mathrm{m})$. 
After the analysis of the results of the cold plastic working tests and after the machining of alloy and composite coatings, it can be concluded that the technologies presented in the article may be recommended for surface finishing of coatings.

\section{References}

1. Specification of application and processing technology of powder coatings ProXon 21021, Castolin - Eutectic 2003

2. Starosta, R. Basis of the production and finishing of composite films in the regeneration processes of machinery and plant used in sea water environment. Publisher of the Gdynia Maritime University, Gdynia, Poland, 2013.

3. Dyl, T. Analysis of the possibility of applying of alloy and composite coatings after plastic working in shipbuilding. Advances in Materials Science. 2014, 14, 4, 82-91.

4. Dyl, T.; Skoblik, R.; Starosta R. The Effect of the Ceramic Dispersion on the Nickel Matrix Composite Coating Properties after Plastic Working. Solid State Phenomena. 2009, 147-149, 813-818.

5. Dyl, T.; Starosta, R.; Skoblik R. Effect of the Unit Pressure on the Selection Parameters of Intermetallic Coatings $\mathrm{NiAl}$ and $\mathrm{Ni}_{3} \mathrm{Al}$ after Plastic Working. Solid State Phenomena. 2010, 165, 19-24.

6. Dyl, T.; Starosta, R. Effect of the Ceramic Dispersion in the Nickel Matrix Composite Coatings on Corrosion Properties after Plastic Working. Solid State Phenomena. 2012, 183, 43-48.

7. Dyl, T.; Starosta, R. The influence of rolling on the distribution of stress and strain in nickel - aluminum alloy coatings. Inżynieria Materiałowa Materials Engineering. 2007, 3-4, $524-526$.

8. Dyl T., Starosta R.: Numerical and experimental research of flat rolling of alloy coatings Ni-Al, Periodical of Mechanical, 2012, 10, 36-40.

9. Rydz, D.; Dyja, H.; Berski, S. The prediction of curvature of bimetallic plate Al-Cu during asymmetrical cold rolling, METALURGIJA. 2003, 42, 4, 261-264.

10. Campo, M.; Carboneras, M.; López, M.D.; Torres, B.; Rodrigo, P.; Otero, E.; Rams, J.; Corrosion resistance of thermally sprayed $\mathrm{Al}$ and $\mathrm{Al} / \mathrm{SiC}$ coatings on $\mathrm{Mg}$. Surface and Coatings Technology. 2009, 203, 3224-3230.

11. Wang, H.-T.; Chen, X.; Bai, X.-B.; Ji, G.-C.; Dong, Z.-X.; Yi, D.-L. Microstructure and properties of cold sprayed multimodal WC-17Co deposits. International Journal of Refractory Metals and Hard Materials. 2014, 45, 196-203.

12. Galvanetto, E.; Borgioli, F.; Galliano, F.P.; Bacci, T. Improvement of wear and corrosion resistance of RPS Ti-TiN coatings by means of thermal oxidation. Surface and Coatings Technology. 2006, 200, 3650 - 3655.

13. Garcia, J. R.; Cuetos, J. M.; Ferna'ndez, E.; Higuera, V. Laser Surface Melting Cr-Ni Coatings, in the Erosive-Corrosive Atmosphere of Boilers. Tribology Letters. 2007, 28, 99-108.

14. Yang, J.; Chen, J.; Zhao, W.; Zhang, P.; Yu, Z.; Li, Y.; Zeng, Z.; Zhou, N. Diode Laser Welding/Brazing of Aluminum Alloy to Steel Using a Nickel Coating. Applied Sciences. 2018, 8, 922.

15. Sierra, C.; Vazquez, A.J.; NiAl coating on carbon steel with an intermediate Ni gradient layer. Surface and Coatings Technology. 2006, 200, 4383-4388.

16. St-Georges, L. Development and characterization of composite Ni-Cr+WC laser cladding. Wear. 2007, 263, 562-566. 
17. Machining powder of sprayed layers 19000, 21000, 12000, Materials of the company "Castolin Eutectic" 2011.

18. Sandvik Coromant catalogues and handbooks. Turning tools, AB Sandvik Coromant, Sandviken, Sweden 2019.

19. Starosta, R.; Charchalis, A.; Dyl, T. The choice of thermal spray technology and burnishing in terms of improving the exploitation properties of centrifugal pump shafts. The report of the research project N504 303537. Gdynia, Poland, 2012 